Article

\title{
Non-Linear Thermal Radiations and Mass Transfer Analysis on the Processes of Magnetite Carreau Fluid Flowing Past a Permeable Stretching/Shrinking Surface under Cross Diffusion and Hall Effect
}

\author{
Asad Ullah ${ }^{1}$, Abdul Hafeez ${ }^{1}$, Wali Khan Mashwani ${ }^{1}$ (D), Ikramullah ${ }^{2}$, Wiyada Kumam ${ }^{3, *}$ (D), \\ Poom Kumam 4,5,*(D) and Muhammad Ayaz ${ }^{6}$ \\ 1 Institute of Numerical Sciences, Kohat University of Science \& Technology, Kohat 26000, Khyber \\ Pakhtunkhwa, Pakistan; asad.ullah@kust.edu.pk (A.U.); hafeezktk875@gmail.com (A.H.); \\ mashwanigr8@gmail.com (W.K.M.) \\ 2 Department of Physics, Kohat University of Science \& Technology, Kohat 26000, Khyber Pakhtunkhwa, \\ Pakistan; ikramullah@kust.edu.pk \\ 3 Program in Applied Statistics, Department of Mathematics and Computer Science, Faculty of Science and \\ Technology, Rajamangala University of Technology Thanyaburi (RMUTT), Thanyaburi, \\ Pathumthani 12110, Thailand \\ 4 Center of Excellence in Theoretical and Computational Science (TaCS-CoE) \& KMUTT Fixed Point Research \\ Laboratory, Room SCL 802 Fixed Point Laboratory, Science Laboratory Building, Departments of \\ Mathematics, Faculty of Science, King Mongkut's University of Technology Thonburi (KMUTT), \\ 126 Pracha-Uthit Road, Bang Mod, Thrung Khru, Bangkok 10140, Thailand \\ 5 Department of Medical Research, China Medical University Hospital, China Medical University, \\ Taichung 40402, Taiwan \\ 6 Department of Mathematics, Abdul Wali Khan University, Mardan 23200, Khyber Pakhtunkhwa, Pakistan; \\ mayazmath@awkum.edu.pk \\ * $\quad$ Correspondence: wiyada.kum@rmutt.ac.th (W.K.); poom.kum@kmutt.ac.th (P.K.)
}

Received: 31 March 2020; Accepted: 11 May 2020; Published: 29 May 2020

\begin{abstract}
The flow of conducting Carreau fluid on a permeable stretching/shrinking surface is analytically investigated by considering the thermal radiation, mass transfer, and cross diffusion effects. A uniform external magnetic field is employed which gives rise to Hall current. The nonlinear PDEs are converted to a set of ODEs using similarity transformations. The developed ODEs are solved using the well established mathematical procedure of Homotopy Analysis Method (HAM). The influence of associated parameters over the state variables of the Carreau fluid are analytically studied and discussed through different graphs. It is found that fluid velocity augments (drops) with the rising power law index and Hall parameter (velocity slip and material parameters). The temperature field increases with the higher Dufour number and radiation parameter values, and decreases with larger Prandtl number. The concentration field augments with the larger Soret number and velocity slip parameter values whereas drops with the rising Schmidt number. The variations in skin friction, local Nusselt and Sherwood numbers are discussed using tables and it is noticed that the mass and heat energy transfer rates are controlled by the varying values of Dufour and Soret parameters. The comparison between present and published work shows complete agreement.
\end{abstract}

Keywords: carreau fluid; stretching/shrinking surface; thermal radiations; magnetic field; hall effect; non-linear radiations; HAM 


\section{Introduction}

The heat energy transfer and boundary layer fluid flow on a stretching and/or shrinking surfaces are the topics of intensive investigations since the basic work performed by Crane [1], because of its immense technological applications. Some of them are: electronic chips and metallic sheets cooling, preparation of plastic sheets, crystal growth, paper production, materials manufacturing and so forth [2,3]. Some important aspects of flowing fluid on stretching surface are addressed by Andersson et al. [4], and Vajravelu [5]. We know that the existence of gradients are necessary for the development of various fluxes which then results in different flows. The heat energy transfer is mainly governed by the Soret effect, in which the temperature gradient causes thermal-diffusion. Cross diffusion is a processes in which a gradient in the concentration of one species produces a flux of another chemical species. In other words, cross diffusion is normally the combined effect of the mass and thermal diffusion. The mass transfer analysis is mainly concerned with the Dufour effect, which causes due to the diffusion-thermo effect. These two effects play a vital role in the natural convection flow. The heat exchangers, steel manufacturing and other cooling phenomena are the prime areas where the convective heat energy transfer flow plays an important and basic role. Liu et al. [6] examined the impact due to convective heat energy transfer over a three-dimensional exponential stretchable surface. The Carreau fluid boundary layer flow has studied by Hayat et al. [7] and concluded that suction enhances (reduces) the thickness (speed) of the fluid. A detailed study on the boundary layer theory can be found in References [8,9].

The study of the fluid dynamics in the magnetic field presence in order to measure the various macroscopic properties of the fluid is called Magneto Hydro Dynamics (MHD). MHD has its wide applications in Plasma Physics, cooling of metallic blankets in reactors, in engineering and technology, in the theoretical explanation of various astrophysical phenomena, and so on. The transfer of heat energy above a vertical and stretching surface during the magnetized flow is examined by Nazar et al. [10] and noticed that the increasing magnetic field strength results in the reduction of the heat energy loss and coefficient of local skin friction. Ishak et al. [11] examined the stagnation flow in the magnetic field presence towards an extending surface. $\mathrm{Xu}$ et al. [12] analytically examined heat transformation during the 3-dimensional magnetized flow on a stretching plate by using series solution technique. Vajravelu et al. [13] studied the convective heat energy transformation over an extendable surface during a magnetized fluid flow. Pop and Na [14] worked on fluid motion over a porous and stretching surface by applying an external magnetic field. For the more recent studies over MHD boundary layer flow, the interested readers are referred to References $[15,16]$.

The analysis of thermal energy radiations is of basic importance in solar energy technology, nuclear energy production, combustion engines and chambers, propulsion engines for high speed aircraft, and chemical process at high operating temperatures. The thermal radiation boundary layer MHD nanofluid flow over an extending surface is examined by Gnaneswara Reddy [17]. Emad [18] examined the effects produced due to the presence of radiations during the flow of electrically conducting fluid. Gnaneswara Reddy [19] investigated the magnetized and mixed convective flow of a boundary layer in a permeable medium by considering the impacts of heat energy source, Ohmic effect, and chemical reaction. The effect of radiation on the heat energy transformation due to convection in conducting (electrically) fluid over an extendable surface having varying viscosity is investigated by Abo-Eldahab and Elgendy [20]. Gnaneswara Reddy [21] examined the effects produced due to Joule heating, thermophoresis and viscous dissipation during a steady and magnetized fluid flow on an inclined, isothermal and permeable surface. Yulin et al. [22] studied numerically the natural convective nanofluid flow inside an inclined enclosure. They studied the impacts of constant temperature and heat source. Zhe et al. [23] studied experimentally the ethylene glycol mixture with water and Copper oxides by using statistical technique for the MWCNTs. Recently, Dat et al. [24] numerically analyzed the $\gamma$-AlOOH nanofluids by considering nanoparticles of various shapes in a wavy channel. The more recent survey on the nanaofluids with applications can be found in References [25-29]. 
Fluids can be broadly classified as Newtonian and non-Newtonian. The Newton law of viscosity which states that there is a direct relation between shear stress and strain is valid in the first type of fluid. Whereas in non-Newtonian fluid this simple direct relationship does not exist. The non-Newtonian fluids are ubiquitous in this industrialized world, for example structured as well as genetic liquid organisms, human blood, polymeric solutions and exotic liquids and so forth. Due to non-linearity, the non-Newtonian liquids are difficult to handle both analytically as well as computationally, as compared to Newtonian liquids. Thanks to Carreau [30], who introduced a constitutive relation which can effectively describe the nonlinear and viscoelastic characteristics of non-Newtonian fluids. Ali and Hayat [31] examined the peristaltic flow of Carreau fluid through a non-symmetrical channel. The effect produced due to the inclusion of induced magnetic force on the Carreau fluid transportation is explained by Hayat et al. [32]. The Carreau fluid motion through an inclined surface is presented by Tshehla [33]. Elahi et al. [34] discussed the 3-dimensional Carreau fluid flow through a duct. The Ohmic heating effect of the magnetized nanofluid viscous flow on a nonlinear porous and extendable surface is analyzed by Gnaneswara Reddy et al. [35]. Jiaqiang et al. [36] used the wetting models by explaining the working mechanism of different surfaces exist in nature. The different aspects due to thermal radiations by considering suction (injection) on the magnetized flow are examined by various researchers [37-39].

The magnetic field application to a conducting fluid results in the production of potential difference, the phenomena is called Hall effect. The effects produced by Hall current in a fluid is investigated by many investigators due to large number of technological applications. Datta and Janna [40] examined the MHD oscillatory flow on a flat surface by taking into account the phenomenon of Hall effect. The detail description of Hall effect in the fluid dynamics on the magnetized flow over a vertical and semi-infinite plate is explained by Aboeldahab and Elbarbary [41]. Biswal and Sahoo [42] studied the Hall current effects during the magnetized flow on a perpendicular and porous oscillatory surface. Raju et al. [43] analyzed the impacts of Hall current over a magnetized flow on a stretching and oscillatory surface with permeable upper wall. The temperature and mass diffusion variations during magnetized flow in the Hall effect presence is explained by Rajput and Kanaujia [44]. Similar study is undertaken by Shah et al. [45-47] using semi-analytical techniques. The MHD peristaltic Carreau-Yasuda fluid dynamics in a curved channel is numerically tackled by Abbasi et al. [48] in the presence of Hall effect.

This study aims to analytically investigate the impact of Hall current and cross diffusion over the heat energy and mass transfer characteristics of magnetized Carreau fluid on a porous stretching (shrinking) surface. This work has potential technological applications in different fields like food processing, polymers preparation, micro-circulatory blood flow and magma flows, and so forth. The novelty of the present research is the analytical exploration and the inclusion of the Hall current over the mass and heat energy transfer properties of the magnetized Carreau fluid flow. In Section 2, the geometry and governing mathematical model of the problem is presented. The basic idea and mechanism of HAM is explained in Section 3. The analytical results are obtained and explained through various graphs in Section 4 . The variations of primary quantities of engineering interest are tabulated and explained in Section 5. The conclusion is given in Section 6.

\section{Mathematical Model of the Problem}

Consider a 2-dimensional, laminar, steady, and in-compressible flow of Carreau fluid over a permeable and stretching surface in the presence of nonlinear thermal radiation and Hall effect. An ambient magnetic field of strength $B_{0}$ is utilized along the horizontal ( $x$-axis) direction, and the fluid under consideration is electrically conducting. The thermal and mass diffusion due to temperature and concentration gradients are also considered. The geometry of the problem is selected in such a manner that the sheet moves along the $x$-axis with velocity $U_{w}$, and the flow is assumed to be along $y \geq 0$ as depicted through Figure 1. 


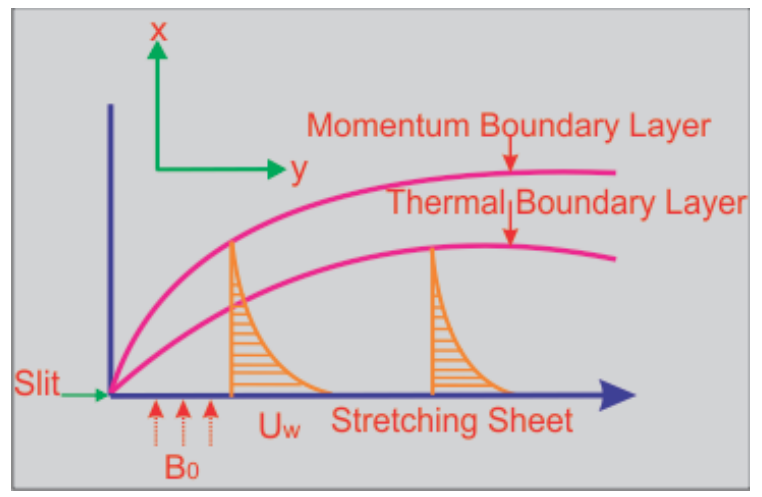

Figure 1. Geometrical description of the study.

The basic relations which governs the Carreau fluid flow is $[30,49]$ :

$$
\tau=\left[\eta_{\infty}+\left(\eta_{0}-\eta_{\infty}\right)\left(1+(\lambda \dot{\gamma})^{2}\right)^{\frac{n-1}{2}}\right] \dot{\gamma}
$$

here, $\eta_{\infty}\left(\eta_{0}\right)$ is the infinite (zero) shear rate viscosity, $\tau$ is the extra stress tensor, $n$ is the index of the power law, $\lambda$ the time constant, and $\gamma$ is defined as below [49]:

$$
\gamma=\sqrt{\frac{1}{2} \sum_{i} \sum_{j} \gamma_{i} j_{j} \gamma_{j}}=\sqrt{\frac{1}{2} \Pi}
$$

where, $\Pi$ is the strain - rate tensor second invariant. Assume $\eta_{\infty}=0$, Equation (1) becomes

$$
\tau=\left[\eta_{0}\left(1+\left(\lambda \gamma^{\cdot}\right)^{2}\right)^{\frac{n-1}{2}}\right] \gamma
$$

The magnetic field application to the conducting fluid produces Hall current, that further affect the fluid flow. This phenomenon is analyzed with the generalized Ohm's law [50,51]

$$
\vec{j}+\frac{\omega_{e}}{B_{0} t_{e}} \times(\vec{j} \times \vec{B})+\frac{\sigma P_{e}}{e n_{e}}=\sigma(\vec{E}+\vec{V} \times \vec{B})
$$

here $\vec{j}$ and $\sigma$ denote the electrical current density and conductivity, $n_{e}$ and $e$ are the number density and charge of electron respectively. The components of the current density vector in the specified geometry take the forms [52]:

$$
\begin{aligned}
& j_{x}=\frac{\sigma B_{0}^{2}(m u-w)}{1+m^{2}} \\
& j_{z}=\frac{\sigma B_{0}^{2}(m w+u)}{1+m^{2}}
\end{aligned}
$$

here, $m=\omega_{e} t_{e}$ denotes the Hall parameter.

Using Equations (3)-(6), the continuity, momentum, energy and concentration equations are presented as respectively [53-55]:

$$
\begin{gathered}
\frac{\partial u}{\partial x}+\frac{\partial v}{\partial y}=0 \\
u \frac{\partial u}{\partial x}+v \frac{\partial u}{\partial y}-v \frac{\partial^{2} u}{\partial y^{2}}\left(1+\left(\frac{n-1}{2}\right) \lambda^{2}\left(\frac{\partial u}{\partial y}\right)^{2}\right)=v(n-1) \lambda^{2} \frac{\partial^{2} u}{\partial y^{2}}\left(\frac{\partial u}{\partial y}\right)^{2} \times\left(1+\left(\frac{n-3}{2}\right) \lambda^{2}\left(\frac{\partial u}{\partial y}\right)^{2}\right) \\
-\frac{\sigma B_{0}^{2} u}{\rho}-\frac{\sigma_{n} f B_{0}^{2}(m w+u)}{\rho\left(1+m^{2}\right)}-\frac{v u}{k}
\end{gathered}
$$




$$
\begin{gathered}
u \frac{\partial T}{\partial x}+v \frac{\partial T}{\partial y}=-\frac{1}{\rho c_{p}} \frac{\partial q_{r}}{\partial y}+\alpha \frac{\partial^{2} T}{\partial y^{2}}+\frac{D_{m} K_{T}}{c_{s} c_{p}} \frac{\partial^{2} C}{\partial y^{2}} \\
u \frac{\partial C}{\partial x}+v \frac{\partial C}{\partial y}=\frac{D_{m} K_{T}}{T_{m}} \frac{\partial^{2} T}{\partial y^{2}}+D_{m} \frac{\partial^{2} C}{\partial y^{2}}
\end{gathered}
$$

The boundary restrictions on the system are given by:

$$
\begin{array}{r}
u=u_{w}(x)+L \frac{\partial u}{\partial y}, v=v_{w}, \frac{\partial T}{\partial y}=-\frac{h_{1}}{k}\left(T_{f}-T\right), \frac{\partial T}{\partial y}=-\frac{h_{2}}{D_{m}}\left(C_{f}-C\right) \text { at } y=0, \\
u \rightarrow 0 T \rightarrow T_{\infty}, C \rightarrow C_{\infty} \text { as } y \rightarrow \infty
\end{array}
$$

where $B_{0}$ is the magnetic field strength, $T$ is the temperature, $\rho$ is the density, $k$ is the thermal conductivity, $c_{s}$ is the susceptibility of concentration, $u_{w}(x)=a x(v)$ is the velocity $x(y)$ component, respectively. Further, $v_{w}$ is the mass transfer velocity, $h_{1}$ and $h_{2}$ are convective heat and mass transfer coefficients, $T_{f}\left(C_{f}\right)$ is temperature (concentration) of the convective fluid.

The heat flux of radiations $q_{r}$ can be given as [56,57]:

$$
q_{r}=-\frac{4 \sigma^{s}}{3 k_{1}} \frac{\partial T^{4}}{\partial y}
$$

where, $\sigma^{\mathcal{S}}$ is the Stefan Boltzmann law constant and $k_{1}$ is the the average absorption coefficient. After Taylor expanding $T^{4}$ about the fixed temperature $T_{0}$, and ignoring $T_{0}^{4}$ and higher terms, we obtain

$$
T^{4}=4 T_{0}^{3} T .
$$

Using Equations (12) and (13), we write

$$
\frac{\partial q_{r}}{\partial y}=-\frac{16 \sigma^{s} T_{0}^{3}}{3 k_{1}} \frac{\partial^{2} T}{\partial y^{2}}
$$

From Equations (9) and (14), we get

$$
u \frac{\partial T}{\partial x}+v \frac{\partial T}{\partial y}-\frac{D_{m} K_{T}}{c_{s} c_{p}} \frac{\partial^{2} C}{\partial y^{2}}=\frac{\partial}{\partial y}\left[\left(\alpha+\frac{16 \sigma^{s}}{3 k_{1}} T_{\infty}^{3}\right) \frac{\partial T}{\partial y}\right]
$$

Introducing the following similarity variable [58]:

$$
\begin{array}{r}
\psi=\sqrt{a v} f(\eta) x, \eta=\sqrt{\frac{a}{v}} y, T-T_{\infty}=\left(T_{f}-T_{\infty}\right) \theta(\eta), \\
C-C_{\infty}=\left(C_{f}-C_{\infty}\right) \phi(\eta) T-T_{\infty}=T_{\infty}\left(\theta_{w}-1\right) \theta, \theta_{w}=\frac{T_{f}}{T_{\infty}}
\end{array}
$$

where $a$ is constant, $\phi, f$ and $\theta$ are the dimensionless concentration, velocity and temperature, respectively and $\psi$ is the stream function given by $u=\frac{\partial \psi}{\partial y}$ and $v=-\frac{\partial \psi}{\partial x}$.

Using the similarity transformations in Equations (7), (8), (12), (15) and (16), we have

$$
\begin{gathered}
f^{\prime \prime \prime}\left[1+\left(\frac{n-1}{2}\right) \lambda_{1} f^{\prime \prime 2}\right]+2 f^{\prime \prime \prime}\left[\left(\frac{n-1}{2}\right) \lambda_{1} f^{\prime \prime 2}\right]\left[1+\left(\frac{n-3}{2}\right) \lambda_{1} f^{\prime \prime 2}\right] \\
+f f^{\prime \prime}-f^{\prime 2}-M f^{\prime}-\frac{M}{1+m^{2}} f^{\prime}-r f^{\prime}=0 \\
\left.\theta^{\prime \prime}\left(1+R\left(1+\left(\theta_{w}-1\right) \theta\right)^{3}\right)+\left(3\left(\theta_{w}-1\right) \theta^{\prime 2}\left(1+\theta_{w}-1\right) \theta\right)^{2}\right)+\operatorname{Pr} f \theta \prime+\operatorname{PrDu} \phi \prime \prime=0 \\
\phi^{\prime \prime}+S c f \phi^{\prime}+S c S r \theta^{\prime \prime}=0
\end{gathered}
$$


With the B.Cs.:

$$
\begin{array}{r}
f^{\prime}=1+\gamma_{1}, f=S, f(0)^{\prime \prime}, \theta \prime=-\gamma_{2}(1-\theta(0)) \phi^{\prime}=-\gamma_{3}(1-\phi(0)) \text { at } \eta=0, \\
f^{\prime} \rightarrow 0, \theta \rightarrow, \phi \rightarrow 0 \text { as } \eta \rightarrow \infty
\end{array}
$$

Here, $\lambda_{1}$ is the parameter of the material, $S$ is the parameter of the mass transfer that demonstrates the suction and injection cases for $S>0$ and $S<0$, respectively. $R$ is the radiation parameter, $P r$, $S_{\mathcal{C}}$ and $D u$ are the Prandtl, Soret, and Dufour numbers, and $\gamma_{2}, \gamma_{3}$ denote the slip parameters of the thermal and concentration profiles, respectively. These parameters are respectively defined as $[59,60]$ :

$$
\begin{array}{r}
\lambda_{1}=\frac{\lambda^{2} x^{2} a^{3}}{v}, S_{c}=\frac{v}{D_{m}}, P_{r}=\frac{v}{a}, R=\frac{16 \sigma * T_{\infty}^{3}}{3 k k_{e}}, D_{u}=\frac{D_{m} K_{T}\left(C_{f}-C_{\infty}\right)}{c_{s} c_{p} v\left(T_{f}-T_{\infty}\right)}, r=-\frac{-v}{a k}, \\
\gamma_{1}=L \sqrt{\frac{a}{v}}, \gamma_{2}=\frac{h_{1}}{k} \sqrt{\frac{a}{v}}, \gamma_{3}=\frac{h_{2}}{D_{m}} \sqrt{\frac{a}{v}}
\end{array}
$$

To compute the basic engineering parameters of interest, the local Sherwood and Nusselt numbers and skin friction are given by $[7,58]$ :

$$
\begin{gathered}
S h_{x}=k^{-1}\left(C_{f}-C_{\infty}\right)^{-1} x m_{s} \\
N u_{x}=k^{-1}\left(T_{f}-T_{\infty}\right)^{-1} x q_{s} \\
C_{f}=2 \tau_{s}\left(\rho u_{w}^{2}\right)^{-1}
\end{gathered}
$$

where, $m_{s}$ and $q_{s}$ are the mass and heat transfers from the surface of the plate, and $\tau_{s}$ is the skin friction, which are defined as $[17,58]$ :

$$
\begin{gathered}
m_{s}=-k\left(\frac{\partial C}{\partial y}\right)_{y=0} \\
q_{s}=\left(q_{r}\right)_{w}-k\left(\frac{\partial T}{\partial y}\right)_{y=0}=\theta(0)^{\prime}\left(1+\frac{1}{R} \theta_{(w)}^{3}\right) \sqrt{\frac{a}{v}}\left(T_{\infty}-T_{w}\right) \\
\tau_{s}=\left[\lambda^{2}\left(\frac{n-1}{2}\right)\left(\frac{\partial u}{\partial y}\left(\frac{\partial u}{\partial y}\right)^{2}+3 \frac{\partial v}{\partial x}\left(\frac{\partial u}{\partial y}\right)^{2}\right]_{y=0} \eta_{0}\right.
\end{gathered}
$$

Using Equations (25)-(27) in Equations (22)-(24), we get:

$$
\begin{gathered}
\operatorname{Sh}\left(\operatorname{Re}_{x}\right)^{-1 / 2}=-\phi(0)^{\prime} \\
N u\left(\operatorname{Re}_{x}\right)^{-1 / 2}=-\left(1+\frac{1}{R} \theta_{(w)}^{3}\right) \theta(0)^{\prime} \\
C_{f}\left(R e_{x}\right)^{1 / 2}=1+f(0)^{\prime \prime} \lambda_{1}\left(\frac{n-1}{2}\right)
\end{gathered}
$$

where $R e_{x}=\frac{u_{w}}{v}$ demonstrates the local Reynolds number.

\section{Solution by HAM}

Nowadays, the numerical techniques which are used for the solution of the non-linear equations normally uses approximations for the non-linear terms or uses discretization or linearization approaches. Problems occur in engineering and technology can not always be tackled with the standard numerical techniques. In the last few decades researcher took an immense interest in the analytical solution of these types of non-linear problems. The basic idea behind the Homotopy Analysis Method is given by Liao [61]. He used a topological concept known as "Homotopy". He used two different continuous functions $\zeta_{1}(\tilde{x})$ and $\zeta_{2}(\tilde{x})$ defined over the two spaces $\hat{X}$ and $\hat{Y}$. The basic theory 
of the transformation is based on linking the closed unit interval with the topological spaces defined, as given below:

$$
\tilde{\Psi}: \hat{X} \times[0,1] \rightarrow \hat{Y}
$$

where $\tilde{\Psi}[\hat{x}, 0]=\zeta_{1}(\hat{x})$ and $\tilde{\Psi}[\hat{x}, 1]=\zeta_{2}(\hat{x})$ holds $\forall \hat{x} \in \hat{X}$. The transformation given in Equation (31) is called homotopic transformation. The set of Equations (17)-(19) with the boundary restrictions (20) are solved with HAM, by choosing suitable initial guesses $f_{0}, \theta_{0}$ and $\phi_{0}$ with the corresponding liner operators defined as:

$$
L_{\bar{f}}(\bar{f})=\bar{f}^{\prime \prime \prime}, L_{\bar{\theta}}(\bar{\theta})=\bar{\theta}^{\prime \prime} \text {, and } L_{\bar{\phi}}(\bar{\phi})=\bar{\phi}^{\prime \prime}
$$

that satisfy

$$
L_{\bar{f}}\left(c_{1}+c_{2} \eta+c_{3} \eta^{2}\right)=0, L_{\bar{\theta}}\left(c_{4}+c_{5} \eta\right)=0, \text { and } L_{\bar{\phi}}\left(c_{6}+c_{7} \eta\right)=0
$$

\section{Results and Discussion}

The basic mechanism of homotopy analysis method (HAM) is described in Section 3. Since 1992, HAM is widely used for solving system of non-linear DEs. The uses and applications of this approach are mainly due to its convergence and wide range for the choice of initial guess $[45,62,63]$. In this work, we used this technique in order to solve the set of Equations (17)-(20). The results are plotted through various graphs to show the influence of various pertinent parameters over the state variables. Furthermore, the obtained and published results are compared, which shows the efficiency of our employed technique.

The effect of the varying values of $M=1,2,3,4$ over the velocity field is described in Figure 2. From the figure it is found that there exists an inverse relation between the fluid velocity and $\eta$ at fixed $M$. Due to the applied magnetic field, Lorentz force appears. The Lorentz force and magnetic parameter are directly related with each other. The Lorentz force acts perpendicular to both the fluid velocity and the external magnetic field, hence retards its motion, as a result the velocity declines. The decline in velocity is much faster for smaller values of $\eta$. By increasing $M$ to higher values, a reduction in the velocity profiles occurs. Therefore, higher value of $M$ reduces the boundary layer thickness, which results a decline in the velocity profile. This decline is almost uniform at higher values of $\eta$.

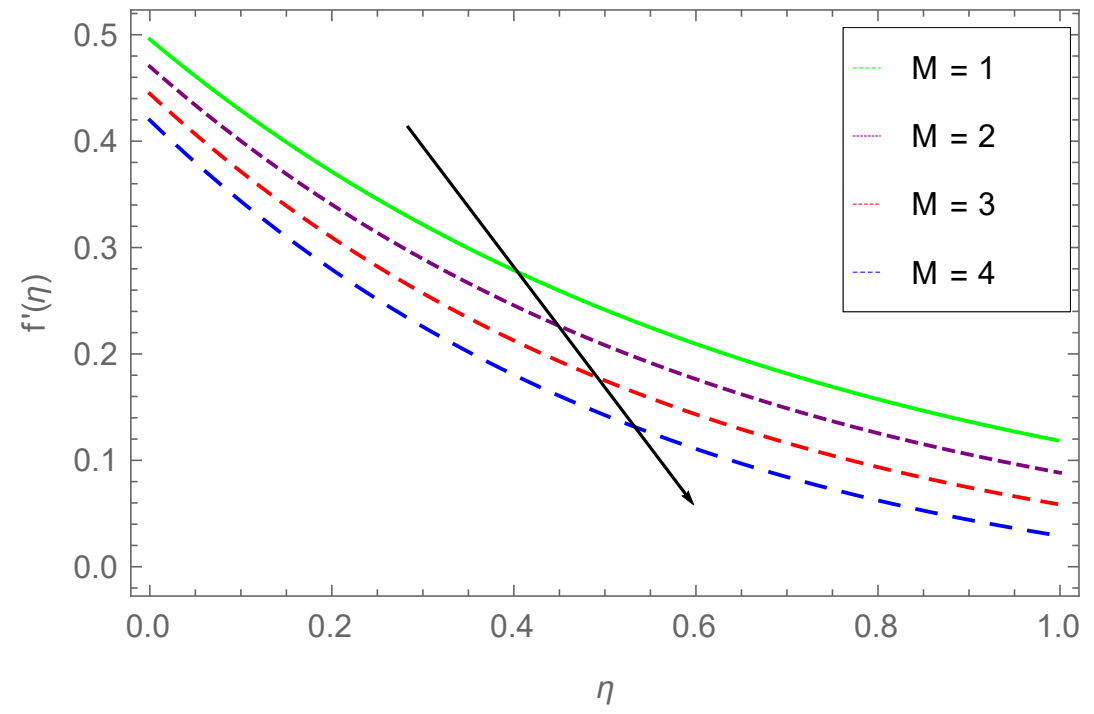

Figure 2. Influence of $M$ on $f^{\prime}(\eta)$.

The variations in the fluid velocity are depicted in Figure 3 for changing the Hall parameter values, that is, $(m=0.1,0.2,0.3,0.4)$. The velocity of the fluid varies inversely with increasing $\eta$ at a fixed Hall parameter $m$. The applied magnetic force produces a self induced current, which affect the velocity of the moving fluid. This effect is more stronger at higher values of $m$. The induced effect is 
in the direction of the flow. Thus, when the Hall parameter increases, the velocity profile augments accordingly. These variations are very effective at larger values of $\eta$.

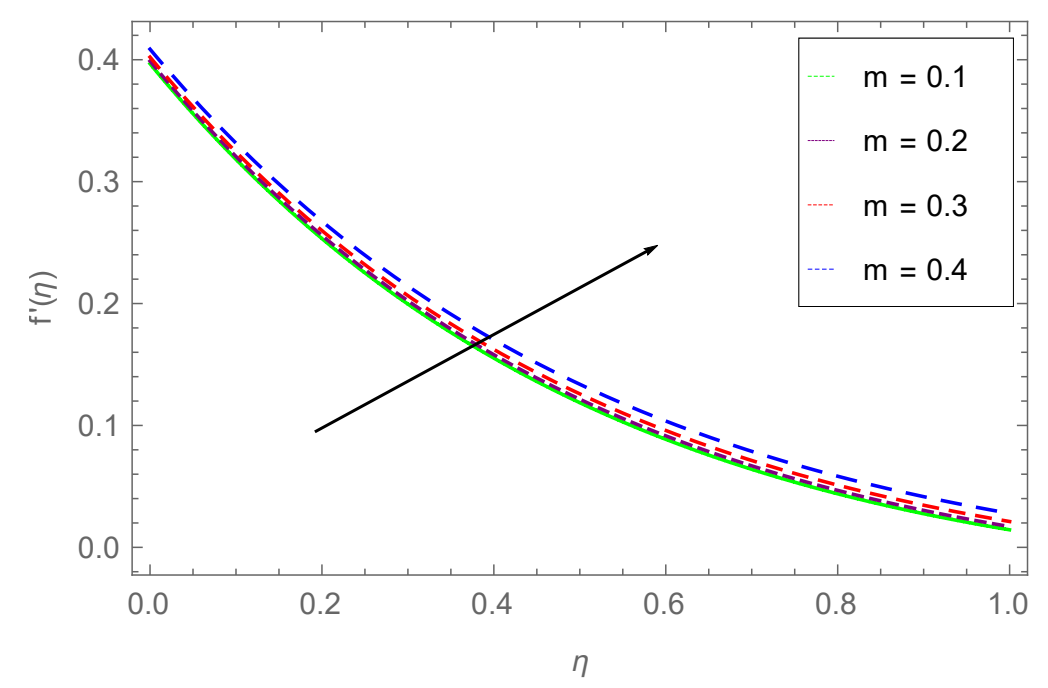

Figure 3. Influence of $m$ over $f^{\prime}(\eta)$.

Figure 4 depicts the fluid velocity $\left(f^{\prime}(\eta)\right)$ for varying $\gamma_{1}$ (velocity slip parameter). From the figure it is seen that, at a given $\gamma_{1}$, the velocity drops as $\eta$ varies from 0 to 1 . The rate at which the velocity drops is larger at smaller $\eta$. By enhancing the parameter $\gamma_{1}$ from 0.1 to $0.3,0.5$ and to 0.7 , the $f^{\prime}(\eta)$ profile drops gradually. The rate at which the velocity profile drops reduces with the rising $\gamma_{1}$. The increasing $\gamma_{1}$ results in higher frictional force which causes the fluid velocity to drop.

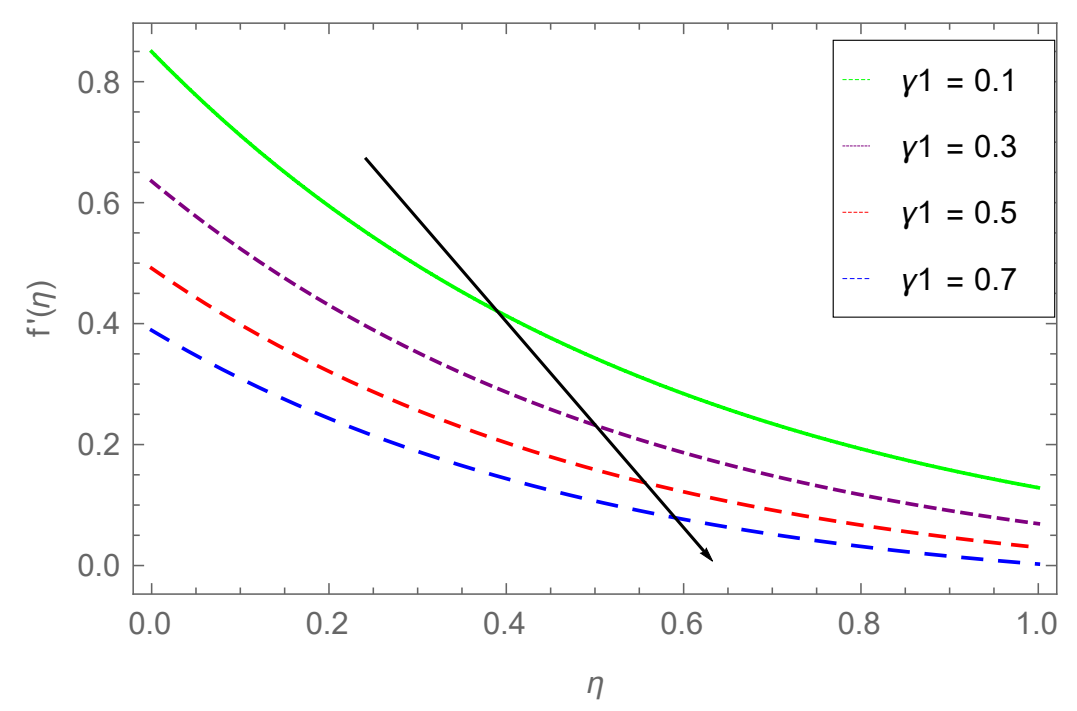

Figure 4. Dependence of $f^{\prime}(\eta)$ over $\gamma_{1}$

The effect of variation of $n$ (power law index) on $\left(f^{\prime}(\eta)\right)$ is plotted in Figure 5. It is observed that the velocity drops almost exponentially at fixed $n$. By varying $n$ from 1 to 5,10 , and finally to 15 , the velocity profile increases almost at the same rate. The non-Newtonian aspects decreases with the rising values of $n$, which causes the enhancement of the fluid velocity . 


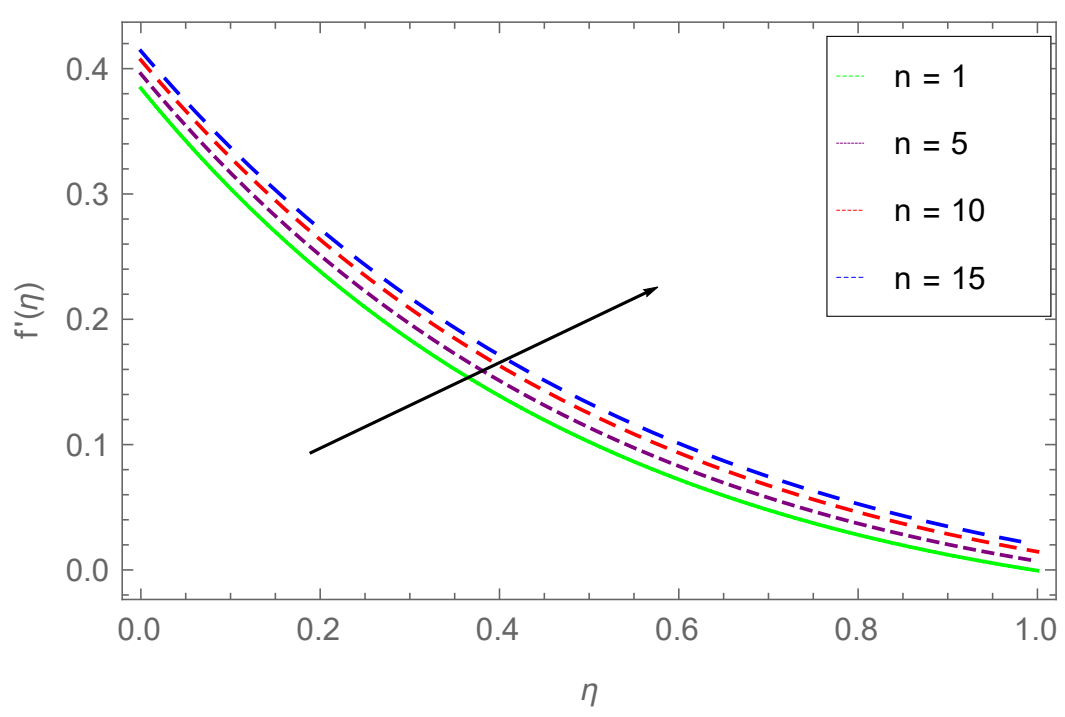

Figure 5. Variation of $f^{\prime}(\eta)$ with $n$.

Figure 6 depicts $f^{\prime}(\eta)$ for changing values of $\lambda_{1}$ (material parameter). $f^{\prime}(\eta)$ decreases with the increasing $\eta$ at constant $\lambda_{1}$. The profile of $f^{\prime}(\eta)$ drops with the enhancing $\lambda_{1}$ values. The rate at which the velocity profile drops with the increasing $\lambda_{1}$ is larger as we go from $\lambda_{1}=1.0$ to $\lambda_{1}=1.5$ in comparison with the higher values of $\lambda_{1}$.

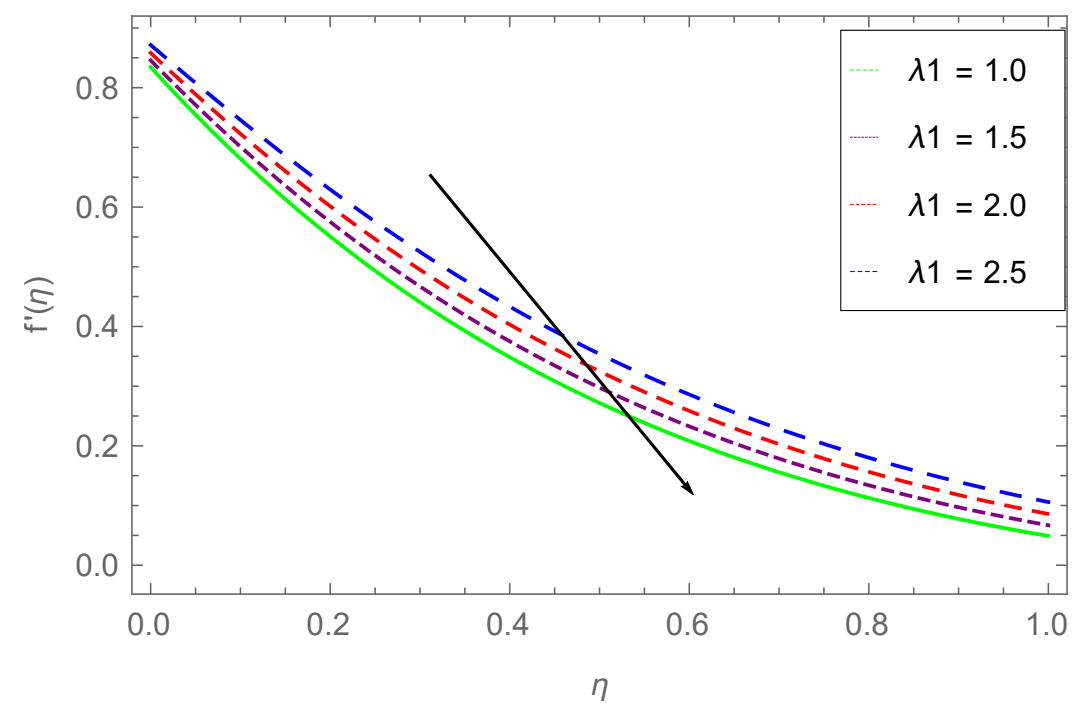

Figure 6. Impact of $\lambda_{1}$ over $f^{\prime}(\eta)$.

The dependence of the temperature field $(\theta(\eta))$ on Dufour number $(D u)$ is depicted in Figure 7. At given $(D u)$ value, the temperature field varies inversely with higher $\eta$ as cleared from the figure. We observe almost the similar increasing trend for the temperature distribution of the fluid with the ascending values of $D u$ as displayed by $f^{\prime}(\eta)$ with the higher power law index $(n)$ values in Figure 5. The spacing between different temperature curves is small at smaller $\eta$ as compared to the spacing at larger $\eta$. The increasing value of $D u$ causes to accumulate the fluid particles, which results in enhancing the fluid temperature due to the increasing probability of inter-particles collisions. 


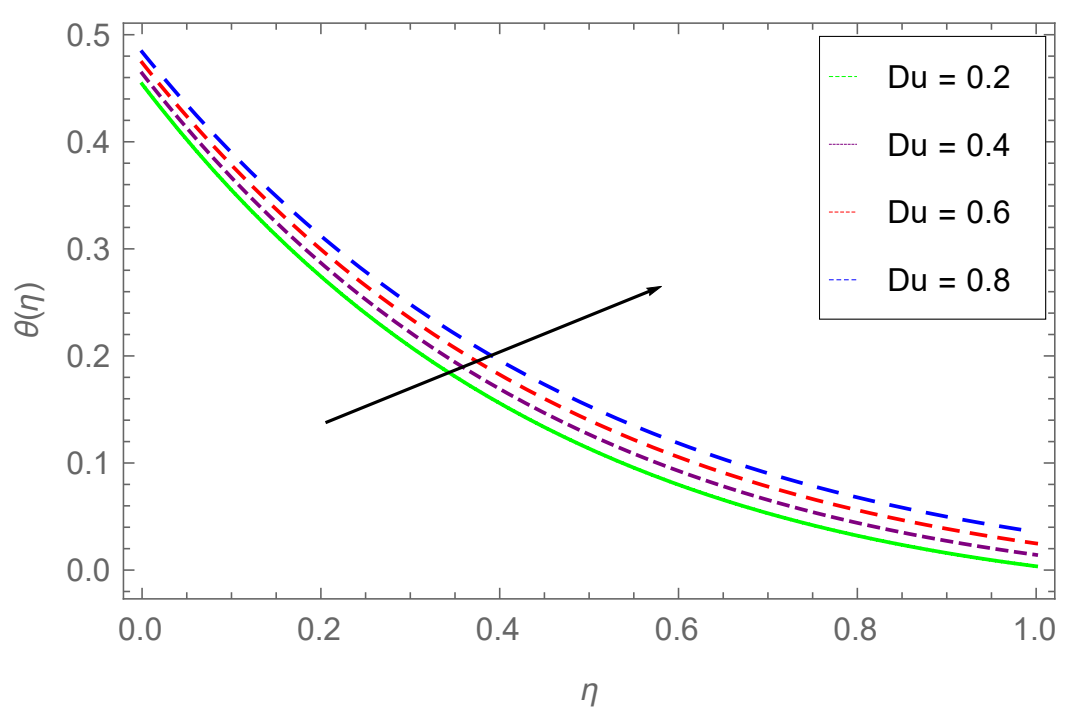

Figure 7. Dependence of $\theta(\eta)$ on $D u$.

The impact of variation of the Prandtl number $(P r)$ on the fluid temperature $(\theta(\eta))$ is plotted in Figure 8. The temperature of the fluid drops with increasing $\eta$ at fixed Prandtl number. The fluid temperature $(\theta(\eta))$ drops with the higher Prandtl number values as can be seen from Figure 8 . The rate at which $\theta(\eta)$ drops increases with higher Prandtl number and is largest for $\operatorname{Pr}=2.0$. The larger $\operatorname{Pr}$ is equivalent to the smaller fluid diffusity, which results reduction in the fluid temperature.

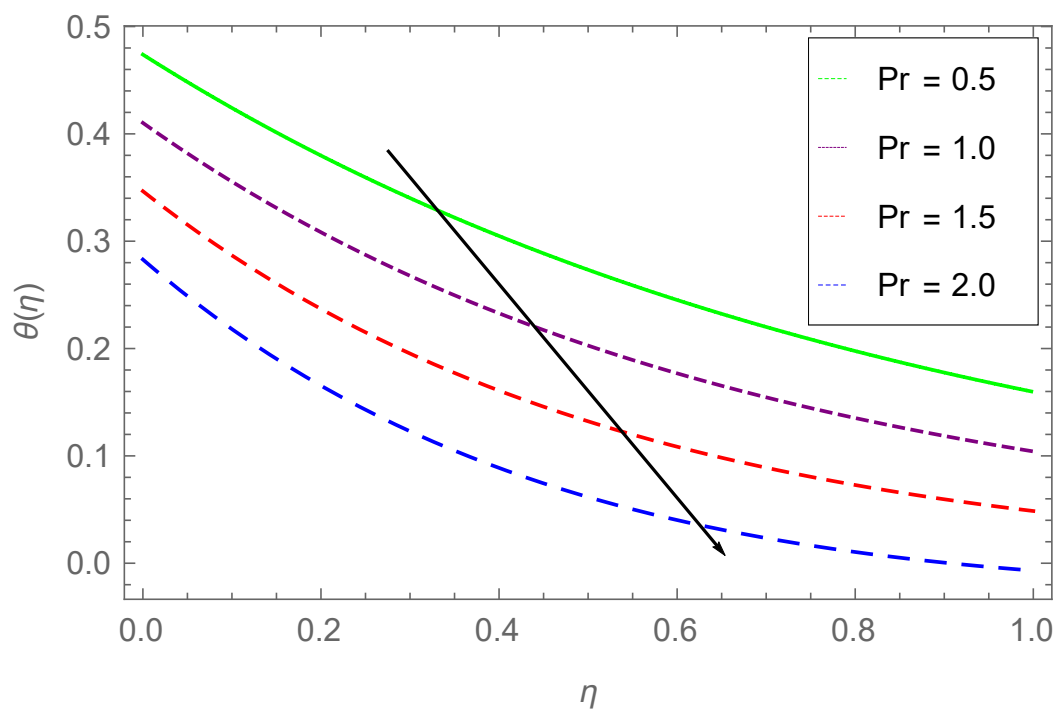

Figure 8. Variatiosn in $\theta(\eta)$ with differnt $P r$.

The temperature of the fluid $(\theta(\eta))$ variation with augmenting values of $R$ (radiation parameter) is plotted in Figure 9. The temperature field varies inversely with $\eta$ at a constant $R$. The changing of $R$ to higher values augments the fluid temperature. The spacing between temperature curves at different $R$ values almost remains constant. The higher radiation parameter resembles a stronger heat source, which causes the enhancement of the fluid temperature. 


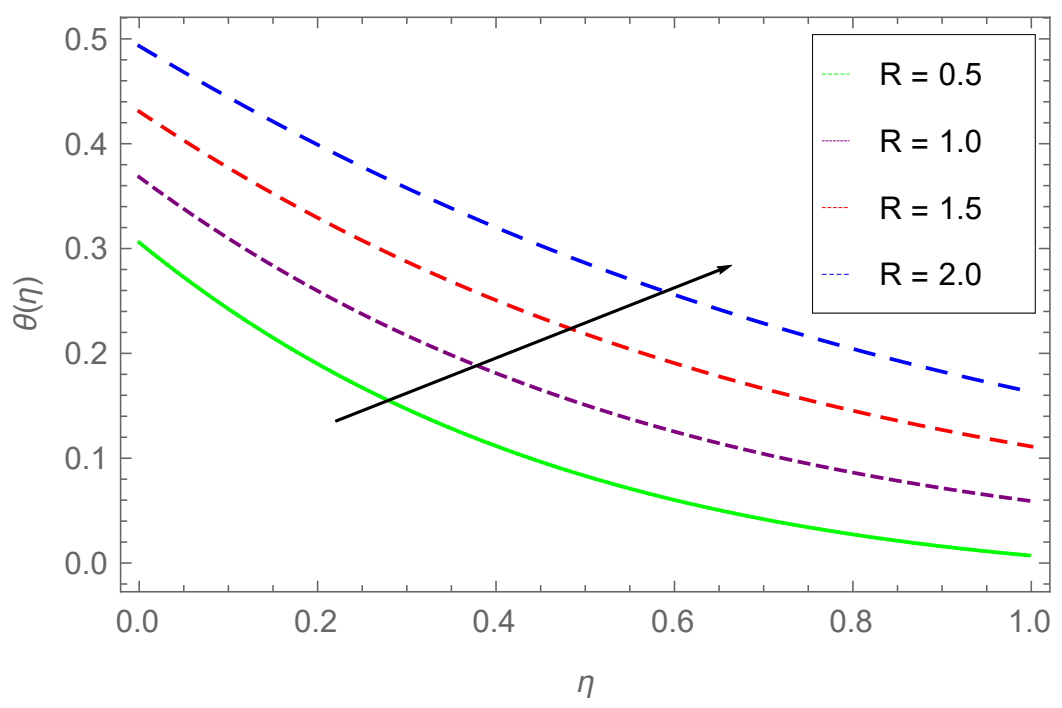

Figure 9. Impact of $R$ over $\theta(\eta)$.

Figure 10 displays the concentration field $(\phi(\eta))$ as a function of $\eta$ for the changing Schmidt number $(S c)$ values. From the figure we see that $\phi(\eta)$ is inversely proportional to $\eta$ at specified value of $S c$. As $S c$ values increase from 0.3 to $0.5,0.7$ and finally to 0.9 , a reducing trend in the concentration profile is observed. The rate of decrease is larger for the highest $S c$. The larger values of Schmidt number are equivalent to smaller mass diffusivity, which results in a reduction in the fluid concentration as is obvious from the figure.

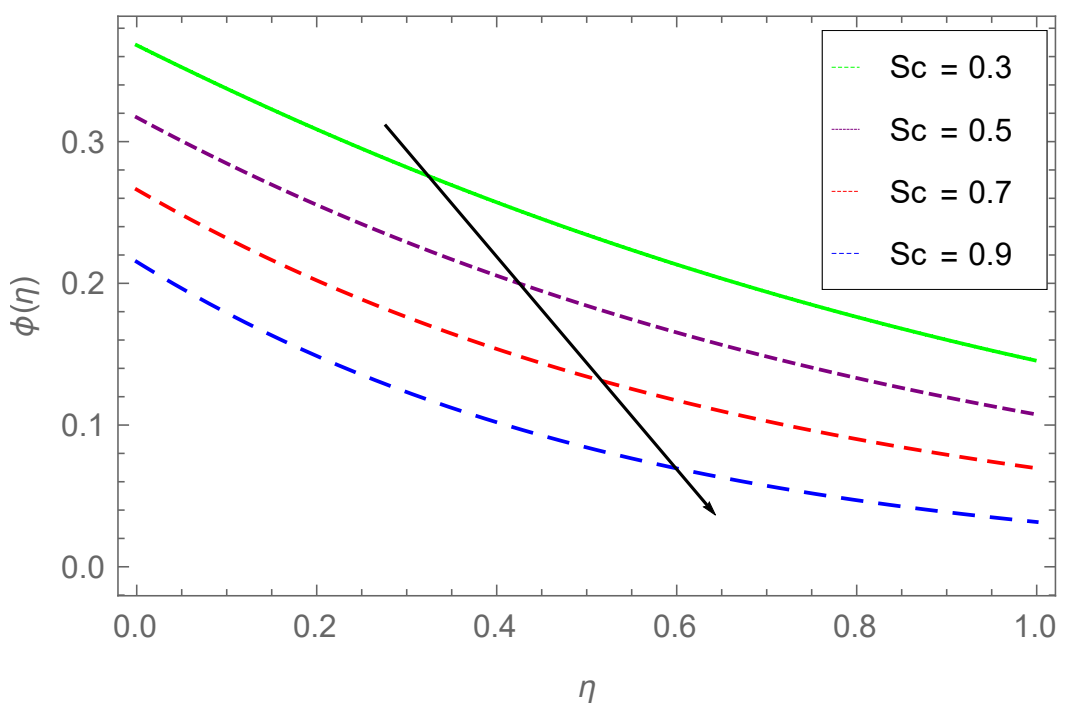

Figure 10. $\phi(\eta)$ versus $S c$.

The variation of the concentration filed $(\phi(\eta))$ of the fluid with various values of $\mathrm{Sr}$ (Soret number) is displayed in Figure 11. The concentration of the fluid decreases with the higher $\eta$ at a given $\mathrm{Sr}$ value. We observe a rise with almost uniform rate in the $\phi(\eta)$ profile with the rising $S r$ values. As $S r$ is associated with the temperature gradient, therefore higher $\mathrm{Sr}$ means larger temperature difference, which causes the concentration profile of the fluid to enhance. 


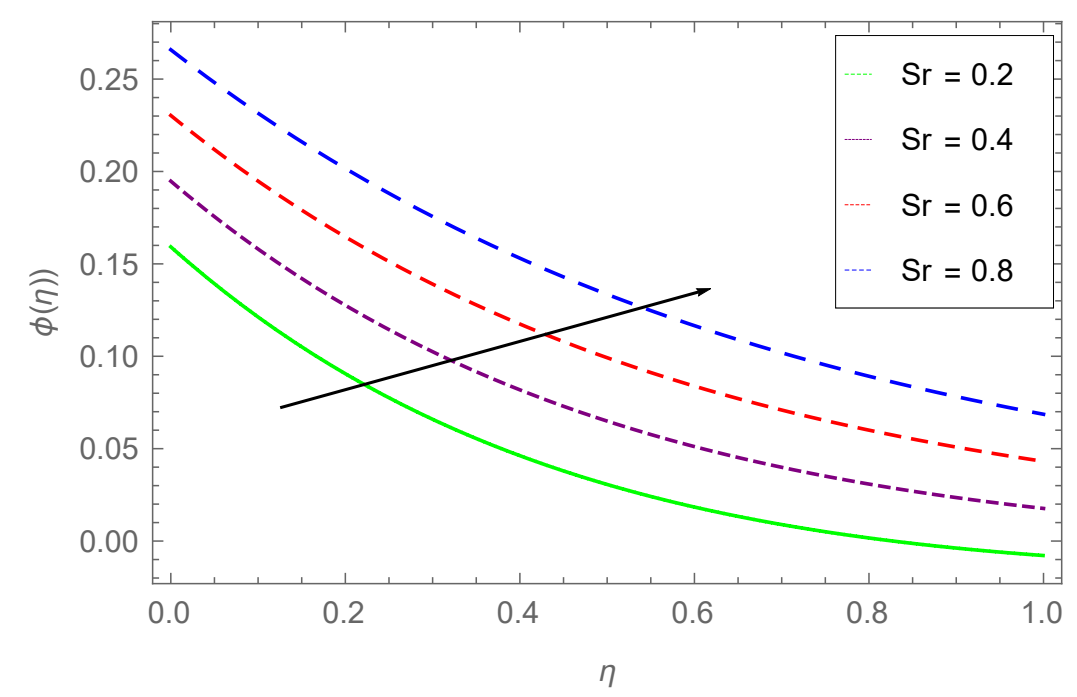

Figure 11. Dependence of $\phi(\eta)$ on $S r$.

Figure 12 displays the relation between the fluid concentration $(\phi(\eta))$ and $\eta$ for rising $\gamma_{1}$ (velocity slip parameter) values. An inverse association exists between $\phi(\eta)$ and $\eta$ at constant $\gamma_{1}$. The concentration profile augments with the higher $\gamma_{1}$ values. The profile enhances almost uniformly with the higher values of $\gamma_{1}$. This means that the larger frictional force drops the fluid velocity which results an enhancement in the concentration profile of the fluid.

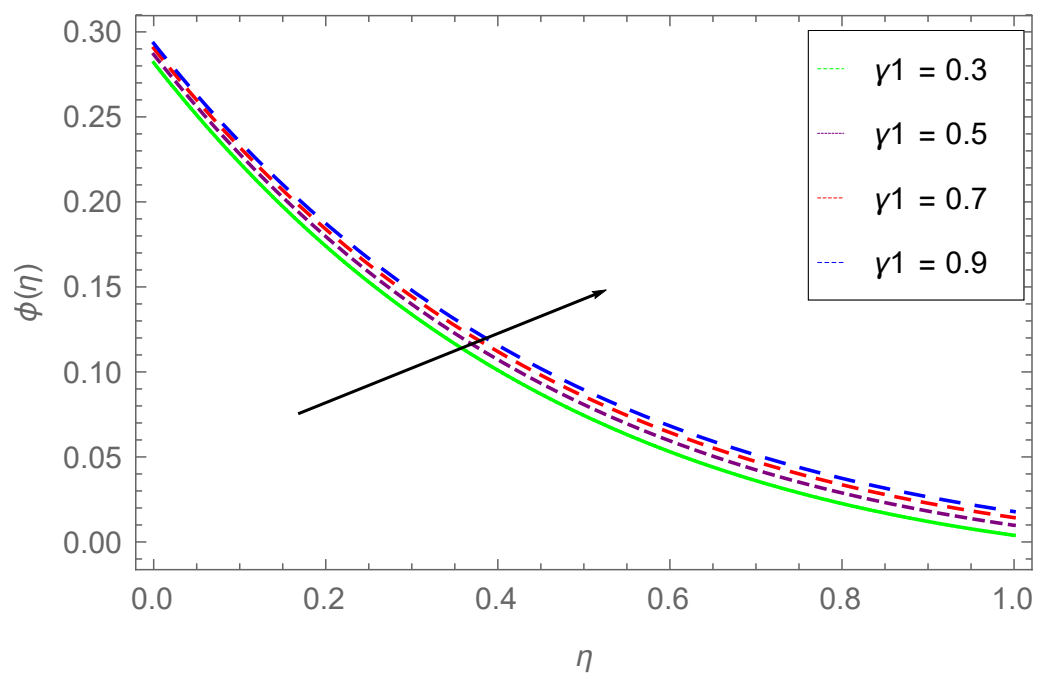

Figure 12. Influence of $\gamma_{1}$ over $\phi(\eta)$.

\section{Tables Discussion}

The comparison of the analytical computations in this research study with the already published results in References $[7,58]$ is displayed through various tables as below.

The comparison of our work with the already published work for the skin friction coefficient for varying values of $S$ and $\lambda_{1}$ is presented in Table 1 . The values of the other parameters $R, S r, D u, M$, and $S c$ are taken 0 . From the table we note that both results are in complete agreement. 
Table 1. Variations in $C_{f}$, for $R=S r=M=D u=S c=D u=0$.

\begin{tabular}{cccc}
\hline $\boldsymbol{S}$ & $\boldsymbol{\lambda}_{\mathbf{1}}$ & Reference [7] & Present Results \\
\hline 0.0 & 0.4 & 0.991339 & 0.9913393 \\
0.3 & 0.4 & 1.15760 & 1.157602 \\
0.6 & 0.4 & 1.34872 & 1.348724 \\
0.6 & 0.0 & 1.34403 & 1.344032 \\
0.6 & 0.2 & 1.34872 & 1.348725 \\
0.6 & 0.4 & 1.33304 & 1.333041 \\
\hline
\end{tabular}

Table 2 describes the comparison for $N u_{x}$ (Nusselt number) for the changing values of, $\lambda_{1}, n, S$ and $P r$, while the values of $R, S r, D u, M$, and $S c$ are considered equal to 0 . Again both computations are in good agreement.

Table 2. Variations in $N u_{x} R=S r=M=S c=D u=0$.

\begin{tabular}{ccccccc}
\hline$\lambda_{1}$ & $n$ & $\boldsymbol{S}$ & $\boldsymbol{P r}$ & $\boldsymbol{\gamma}$ & Reference [7] & Present Results \\
\hline 0.0 & 0.6 & 0.6 & 0.2 & 0.2 & 0.166837 & 0.1668374 \\
0.1 & 0.6 & 0.6 & 0.2 & 0.2 & 0.1666775 & 0.1666775 \\
0.2 & 0.6 & 0.6 & 0.2 & 0.2 & 0.474120 & 0.4741203 \\
0.2 & 0.3 & 0.7 & 1.3 & 0.2 & 0.166631 & 0.1666314 \\
0.2 & 0.5 & 0.7 & 1.3 & 0.2 & 0.166691 & 0.1666914 \\
0.2 & 0.7 & 0.7 & 1.3 & 0.2 & 0.166750 & 0.1667505 \\
\hline
\end{tabular}

In Table 3 compares the results for $S h_{x}$ (local Sherwood number) for varying $S r$. We have used $D u=\lambda_{1}=0$. The table shows that the results obtained through both computations are in complete agreement.

Table 3. Comparison of the $S h_{x}$ results, for $D u=\lambda=0$.

\begin{tabular}{ccccccc}
\hline$S \boldsymbol{r}$ & $\boldsymbol{n}$ & $\boldsymbol{R}$ & $\boldsymbol{P r}$ & $\boldsymbol{M}$ & Reference [58] & Present Results \\
\hline 0.5 & 0.6 & 0.5 & 0.75 & 0.75 & 1.21108 & 1.2110832 \\
1.0 & 0.6 & 0.5 & 0.75 & 0.75 & 1.0581 & 1.058124 \\
1.5 & 0.6 & 0.5 & 0.75 & 0.75 & 0.9053 & 0.905314 \\
0.2 & 0.6 & 0.5 & 0.75 & 0.75 & 0.7525 & 0.752515 \\
\hline
\end{tabular}

Variations in $C_{f}, N u_{x}$ and $S h_{x}$ with the increasing values o $M, n, S r, D u, R$ and $\gamma_{1}$ for suction are displayed in Table 4 . These quantities enhance with the increasing values of $n$ (power law index) and drop with augmenting $M$. The skin friction coefficient first augments and then reduces, while the Nusselt and Sherwood numbers drop with augmenting $S r$ values. The higher values of diffusion coefficient augment and then drop the Skin friction and Sherwood number, while reduces the Nusselt number. The augmenting values of $R$ reduce both the $C_{f}$ coefficient and $N u_{x}$, whereas enhances $S h_{x}$. The exact opposite behavior is seen for the higher $\gamma_{1}$ values.

The variation of these three quantities $\left(C_{f}, N u_{x}\right.$ and $\left.S h_{x}\right)$ with the augmenting $n, S r, M, R, D u$ and $\gamma_{1}$ for the blowing case displayed in Table 5 . It is observed that these three quantities, namely, the skin friction, local Nusselt and Sherwood numbers, drop (enhance) with the increasing values of magnetic parameter $M(n)$. The $C_{f}$ coefficient remains constant, $N u_{x}$ decreases and $S h_{x}$ decreases (augments) with the higher values of both $S r$ and $D u$, respectively. The higher values of $R$ reduce both the $C_{f}$ coefficient and $N u_{x}$, whereas enhances $S h_{x}$. An exactly opposite trend is seen for the higher $\gamma_{1}$ values. 
Table 4. Variations in $C_{f}, N u_{x}$ and $S h_{x}$ for the suction case.

\begin{tabular}{ccccccccc}
\hline $\boldsymbol{M}$ & $\boldsymbol{n}$ & $\boldsymbol{S r}$ & $\boldsymbol{D} \boldsymbol{u}$ & $\boldsymbol{R}$ & $\gamma_{\boldsymbol{1}}$ & $\boldsymbol{R} \boldsymbol{e}_{\boldsymbol{x}}^{\frac{1}{2}} \boldsymbol{C}_{\boldsymbol{f}}$ & $\boldsymbol{N u} \boldsymbol{u} \boldsymbol{R} \boldsymbol{e}_{\boldsymbol{x}}^{\frac{-\mathbf{1}}{2}}$ & $\boldsymbol{S h} / \boldsymbol{R} \boldsymbol{e}_{\boldsymbol{x}}^{\frac{-1}{2}}$ \\
\hline 1 & - & - & - & - & - & -0.950678 & 0.125518 & 0.150193 \\
2 & - & - & - & - & - & -1.069653 & 0.120818 & 0.147393 \\
3 & - & - & - & - & - & -1.168544 & 0.116819 & 0.144993 \\
- & 1 & - & - & - & - & -1.085312 & 0.120461 & 0.147167 \\
- & 5 & - & - & - & - & -0.970058 & 0.123213 & 0.148882 \\
- & 10 & - & - & - & - & -0.853761 & 0.126262 & 0.150757 \\
- & - & 0.2 & - & - & - & -1.069652 & 0.127662 & 0.155867 \\
- & - & 0.4 & - & - & - & -1.069651 & 0.122989 & 0.150090 \\
- & - & 0.6 & - & - & - & -1.069653 & 0.118758 & 0.143891 \\
- & - & - & 0.2 & - & - & -1.069652 & 0.139853 & 0.146271 \\
- & - & - & 0.4 & - & - & -1.069651 & 0.126867 & 0.148472 \\
- & - & - & 0.6 & - & - & -1.069654 & 0.115051 & 0.146580 \\
- & - & - & - & 0.5 & - & -1.069651 & 0.125799 & 0.147390 \\
- & - & - & - & 1.0 & - & -1.069651 & 0.120819 & 0.148126 \\
- & - & - & - & 1.5 & - & -1.069653 & 0.116279 & 0.149515 \\
- & - & - & - & - & 0.1 & -1.220020 & 0.124010 & 0.145515 \\
- & - & - & - & - & 0.3 & -0.954323 & 0.118002 & 0.143293 \\
- & - & - & - & - & 0.5 & -0.788011 & 0.113204 & 0.142297 \\
\hline
\end{tabular}

Table 5. $C_{f}, N u_{x}$, and $S h_{x}$ for the blowing case.

\begin{tabular}{ccccccccc}
\hline $\boldsymbol{M}$ & $\boldsymbol{n}$ & $\boldsymbol{S r}$ & $\boldsymbol{D} \boldsymbol{u}$ & $\boldsymbol{R}$ & $\gamma_{\boldsymbol{1}}$ & $\boldsymbol{R e}_{x}^{\frac{1}{2}} C_{f}$ & $\boldsymbol{N u} / \boldsymbol{R} \boldsymbol{e}_{x}^{\frac{-1}{2}}$ & $S \boldsymbol{S h} / \boldsymbol{R} \boldsymbol{e}_{x}^{\frac{-1}{2}}$ \\
\hline 1 & - & - & - & - & - & -0.889776 & 0.114028 & 0.139181 \\
2 & - & - & - & - & - & -1.011871 & 0.106677 & 0.134409 \\
3 & - & - & - & - & - & -1.113430 & 0.100334 & 0.130193 \\
- & 1 & - & - & - & - & -1.025844 & 0.106198 & 0.134071 \\
- & 5 & - & - & - & - & -0.922493 & 0.109861 & 0.136627 \\
- & 10 & - & - & - & - & -0.817218 & 0.113931 & 0.139391 \\
- & - & 0.2 & - & - & - & -1.011874 & 0.113041 & 0.142802 \\
- & - & 0.4 & - & - & - & -1.011874 & 0.108654 & 0.137044 \\
- & - & 0.6 & - & - & - & -1.011874 & 0.104832 & 0.131925 \\
- & - & - & 0.2 & - & - & -1.011874 & 0.125738 & 0.130361 \\
- & - & - & 0.4 & - & - & -1.011874 & 0.112658 & 0.133111 \\
- & - & - & 0.6 & - & - & -1.011874 & 0.101036 & 0.135657 \\
- & - & - & - & 0.5 & - & -1.011872 & 0.111641 & 0.133395 \\
- & - & - & - & 1.0 & - & -1.011874 & 0.106677 & 0.134407 \\
- & - & - & - & 1.5 & - & -1.011874 & 0.102281 & 0.135322 \\
- & - & - & - & - & 0.1 & -1.147816 & 0.110879 & 0.137607 \\
- & - & - & - & - & 0.3 & -0.906699 & 0.102933 & 0.131509 \\
- & - & - & - & - & 0.5 & -0.753593 & 0.096511 & 0.126388 \\
\hline
\end{tabular}

\section{Conclusions}

The work is concluded in this section. The heat and mass transfer characteristics of magnetized Carreu fluid over a permeable and stretching (shrinking) surface are carried out by considering the nonlinear thermal radiations, cross diffusion and Hall effects. The system of given PDEs is converted to ODEs through suitable similarity transformations. The developed ODEs are analytically solved through HAM. The influence of pertinent parameters of interest on the velocity, temperature and concentration fields are investigated and explained graphically. The dependence of skin friction coefficient, local Nusselt and Sherwood numbers on these parameters is described in the tables. The following facts are observed during this investigation.

- The velocity field $\left(f^{\prime}(\eta)\right)$ drops with the ascending values of $M, \gamma_{1}$ and $\lambda_{1}$, while it is enhanced with the Hall effect parameter and $n$ (power law index). 
- The temperature of the Carreu fluid is augmented with the rising values of $D u$ and $R$, whereas it drops with rising Prandtl number values.

- The fluid concentration rises with increasing values of $S r$ and $\gamma_{1}$, and drops with the larger values of $S c$.

- The skin friction coefficient, local Nusselt Number and Sherwood number depreciate (augment) with the larger values of the magnetic parameter (index of the power law, $n$ ) in both cases.

- The Soret number and diffusion coefficient control the heat energy and mass transfer flow rates.

- The augmenting values of radiation parameter reduce both the $C_{f}$ and $N u_{x}$, whereas they enhance $S h_{x}$ in both cases. The rising values of the velocity slip parameter affect these quantities in the opposite manner.

- The agreement between our results and published results confirms the accuracy of the employed procedure.

Author Contributions: Conceptualization, A.U.; Software, A.H.; Writing-Original Draft Preparation, I.; Writing-Review and Editing, M.A. and W.K.M.; Formal Analysis, W.K.M. and M.A.; Validation, I., A.H., and A.U.; Methodology, A.U. and W.K.M.; Investigation, W.K. and M.A.; Resources, P.K. and W.K.; Project Administration, P.K. and W.K.; Funding Acquisition, P.K. All authors have read and agreed to the published version of the manuscript.

Funding: The project was supported by the Center of Excellence in Theoretical and Computational Science (TaCS-CoE), Faculty of Science, King Mongkut's University of Technology Thonburi (KMUTT).

Acknowledgments: The authors are thankful to anonymous reviewers for their fruitful suggestion which improved the quality of the manuscript.

Conflicts of Interest: The authors declare no conflict of interest.

\section{Abbreviations}

The below mentioned parameters and abbreviations with their possible dimensions are used in this article:

$\begin{array}{ll}\sigma & \text { Electrical conductivity } \frac{\mathrm{S}}{\mathrm{m}} \\ B & \text { Uniform magnetic parameter strength } \mathrm{T} \\ N u_{x} & \text { Local Nusslet number } \\ R e_{x} & \text { Local Reynolds number } \\ C_{f} & \text { Skin friction } \\ S h & \text { Sherwood number } \\ m & \text { Hall parameter } \frac{\mathrm{m}^{3}}{\mathrm{C}} \\ S & \text { Mass transfer parameter } \\ P r & \text { Prandtl number } \\ U_{w} & \text { Stretching velocity }\left(\frac{\mathrm{m}}{\mathrm{s}}\right) \\ T & \text { Fluid temperature }(\mathrm{K}) \\ v & \text { Kinematic viscosity } \frac{\mathrm{m}^{2}}{\mathrm{~s}} \\ \rho & \text { Density }\left(\frac{\mathrm{kg}_{\mathrm{m}}}{\mathrm{m}}\right) \\ \mu & \text { Dynamic viscosity mPa } \\ C_{p} & \text { Specific heat }\left(\frac{\mathrm{J}}{\mathrm{kg} \mathrm{K}}\right) \\ J_{w} & \text { Mass flux }\left(\frac{\mathrm{kg}}{\mathrm{sm}}\right) \\ f & \text { Dimensionless velocity } \\ \theta & \text { Dimensionless temperature } \\ \phi & \text { Dimensionless concentration } \\ \infty & \text { Condition at infinity } \\ 0 & \text { Reference condition } \\ x, y, \text { and } z & \text { Coordinates }(\mathrm{m}) \\ \eta & \text { Similarity variable } \\ \gamma & \text { Thermal relaxation parameter } \\ S c & \text { Schmidt number } \\ D u & \text { Dufour number } \\ & \end{array}$


$t \quad$ Time (s)

$n \quad$ Power law index

M Magnetic field interaction parameter

$\tau \quad$ Extra stress tensor

$\Gamma \quad$ Strain rate tensor

$\sigma^{s} \quad$ Stefan Boltzmann constant

$h_{1} \quad$ Convective heat transfer coefficient

$h_{2} \quad$ Convective mass transfer coefficient

$m_{S} \quad$ Surface mass transfer

$q_{s} \quad$ Surface heat transfer

$\gamma_{2}$ Thermal profile slip parameter

$\gamma_{3}$ Concentration profile slip parameter

\section{References}

1. Crane, L.J. Flow past a stretching plate. Z. Angew. Math. Phys. ZAMP 1970, 21, 645-647. [CrossRef]

2. Moradikazerouni, A.; Afrand, M.; Alsarraf, J.; Mahian, O.; Wongwises, S.; Tran, M.D. Comparison of the effect of five different entrance channel shapes of a micro-channel heat sink in forced convection with application to cooling a supercomputer circuit board. Appl. Therm. Eng. 2019, 150, 1078-1089. [CrossRef]

3. Moradikazerouni, A.; Afrand, M.; Alsarraf, J.; Wongwises, S.; Asadi, A.; Nguyen, T.K. Investigation of a computer CPU heat sink under laminar forced convection using a structural stability method. Int. J. Heat Mass Transf. 2019, 134, 1218-1226. [CrossRef]

4. Eid, M.R.; Mahny, K.L. Flow and heat transfer in a porous medium saturated with a Sisko nanofluid over a nonlinearly stretching sheet with heat generation/absorption. Heat Transf. Asian Res. 2018, 47, 54-71. [CrossRef]

5. Vajravelu, K. Viscous flow over a nonlinearly stretching sheet. Appl. Math. Comput. 2001, 124, $281-288$. [CrossRef]

6. Liu, I.C.; Wang, H.H.; Peng, Y.F. Flow and heat transfer for three-dimensional flow over an exponentially stretching surface. Chem. Eng. Commun. 2013, 200, 253-268. [CrossRef]

7. Hayat, T.; Asad, S.; Mustafa, M.; Alsaedi, A. Boundary layer flow of Carreau fluid over a convectively heated stretching sheet. Appl. Math. Comput. 2014, 246, 12-22. [CrossRef]

8. Schlichting, H.; Gersten, K. Boundary-Layer Theory; Springer: Berlin/Heidelberg, Germany, 2016.

9. Dash, G.; Tripathy, R.; Rashidi, M.; Mishra, S. Numerical approach to boundary layer stagnation-point flow past a stretching/shrinking sheet. J. Mol. Liq. 2016, 221, 860-866. [CrossRef]

10. Ishak, A.; Nazar, R.; Pop, I. Hydromagnetic flow and heat transfer adjacent to a stretching vertical sheet. Heat Mass Transf. 2008, 44, 921. [CrossRef]

11. Ishak, A.; Jafar, K.; Nazar, R.; Pop, I. MHD stagnation point flow towards a stretching sheet. Phys. A Stat. Mech. Its Appl. 2009, 388, 3377-3383. [CrossRef]

12. Xu, H.; Liao, S.J.; Pop, I. Series solutions of unsteady three-dimensional MHD flow and heat transfer in the boundary layer over an impulsively stretching plate. Eur. J. Mech. B/Fluids 2007, 26, 15-27. [CrossRef]

13. Vajravelu, K.; Hadjinicolaou, A. Convective heat transfer in an electrically conducting fluid at a stretching surface with uniform free stream. Int. J. Eng. Sci. 1997, 35, 1237-1244. [CrossRef]

14. Pop, I.; Na, T.Y. A note on MHD flow over a stretching permeable surface. Mech. Res. Commun. 1998, 25, 263-269. [CrossRef]

15. Freidoonimehr, N.; Rashidi, M.M.; Mahmud, S. Unsteady MHD free convective flow past a permeable stretching vertical surface in a nano-fluid. Int. J. Therm. Sci. 2015, 87, 136-145. [CrossRef]

16. Khan, M.S.; Karim, I.; Islam, M.S.; Wahiduzzaman, M. MHD boundary layer radiative, heat generating and chemical reacting flow past a wedge moving in a nanofluid. Nano Converg. 2014, 1, 20. [CrossRef] [PubMed]

17. Reddy, M.G. Influence of magnetohydrodynamic and thermal radiation boundary layer flow of a nanofluid past a stretching sheet. J. Sci. Res. 2014, 6, 257-272. [CrossRef]

18. AboEldahab, E.M. Radiation effect on heat transfer in an electrically conducting fluid at a stretching surface with a uniform free stream. J. Phys. D Appl. Phys. 2000, 33, 3180. [CrossRef] 
19. Gnaneswara Reddy, M. Thermal radiation and chemical reaction effects on MHD mixed convective boundary layer slip flow in a porous medium with heat source and Ohmic heating. Eur. Phys. J. Plus 2014, 129, 41. [CrossRef]

20. Abo-Eldahab, E.M.; El Gendy, M.S. Radiation effect on convective heat transfer in an electrically conducting fluid at a stretching surface with variable viscosity and uniform free stream. Phys. Scr. 2000, 62, 321. [CrossRef]

21. Reddy, M.G. Effects of thermophoresis, viscous dissipation and Joule heating on steady MHD Flow over an inclined radiative isothermal permeable surface with variable thermal conductivity. J. Appl. Fluid Mech. 2014, 7. [CrossRef]

22. Ma, Y.; Shahsavar, A.; Moradi, I.; Rostami, S.; Moradikazerouni, A.; Yarmand, H.; Zulkifli, N.W.B.M. Using finite volume method for simulating the natural convective heat transfer of nano-fluid flow inside an inclined enclosure with conductive walls in the presence of a constant temperature heat source. Phys. A Stat. Mech. Its Appl. 2019, 123035. [CrossRef]

23. Tian, Z.; Rostami, S.; Taherialekouhi, R.; Karimipour, A.; Moradikazerouni, A.; Yarmand, H.; Zulkifli, N.W.B.M. Prediction of rheological behavior of a new hybrid nanofluid consists of copper oxide and multi wall carbon nanotubes suspended in a mixture of water and ethylene glycol using curve-fitting on experimental data. Phys. A Stat. Mech. Its Appl. 2020, 124101. [CrossRef]

24. Vo, D.D.; Alsarraf, J.; Moradikazerouni, A.; Afrand, M.; Salehipour, H.; Qi, C. Numerical investigation of $\gamma$-AlOOH nano-fluid convection performance in a wavy channel considering various shapes of nanoadditives. Powder Technol. 2019, 345, 649-657. [CrossRef]

25. Alsarraf, J.; Moradikazerouni, A.; Shahsavar, A.; Afrand, M.; Salehipour, H.; Tran, M.D. Hydrothermal analysis of turbulent boehmite alumina nanofluid flow with different nanoparticle shapes in a minichannel heat exchanger using two-phase mixture model. Phys. A Stat. Mech. Its Appl. 2019, 520, 275-288. [CrossRef]

26. Moradikazerouni, A.; Hajizadeh, A.; Safaei, M.R.; Afrand, M.; Yarmand, H.; Zulkifli, N.W.B.M. Assessment of thermal conductivity enhancement of nano-antifreeze containing single-walled carbon nanotubes: Optimal artificial neural network and curve-fitting. Phys. A Stat. Mech. Its Appl. 2019, 521, 138-145. [CrossRef]

27. Asadi, A.; Aberoumand, S.; Moradikazerouni, A.; Pourfattah, F.; Żyła, G.; Estellé, P.; Mahian, O.; Wongwises, S.; Nguyen, H.M.; Arabkoohsar, A. Recent advances in preparation methods and thermophysical properties of oil-based nanofluids: A state-of-the-art review. Powder Technol. 2019, 352, 209-226. [CrossRef]

28. Ranjbarzadeh, R.; Moradikazerouni, A.; Bakhtiari, R.; Asadi, A.; Afrand, M. An experimental study on stability and thermal conductivity of water/silica nanofluid: Eco-friendly production of nanoparticles. J. Clean. Prod. 2019, 206, 1089-1100. [CrossRef]

29. Shi, E.; Zang, X.; Jiang, C.; Mohammadpourfard, M. Entropy generation analysis for thermomagnetic convection of paramagnetic fluid inside a porous enclosure in the presence of magnetic quadrupole field. J. Therm. Anal. Calorim. 2020, 139, 2005-2022. [CrossRef]

30. Carreau, P.J. Rheological equations from molecular network theories. Trans. Soc. Rheol. 1972, 16, 99-127.

31. Ali, N.; Hayat, T. Peristaltic motion of a Carreau fluid in an asymmetric channel. Appl. Math. Comput. 2007, 193, 535-552. [CrossRef]

32. Hayat, T.; Saleem, N.; Ali, N. Effect of induced magnetic field on peristaltic transport of a Carreau fluid. Commun. Nonlinear Sci. Numer. Simul. 2010, 15, 2407-2423. [CrossRef]

33. Tshehla, M. The flow of Carreau fluid down an incline with a free surface. Int. J. Phys. Sci. 2011, 6, 3896-3910. [CrossRef]

34. Ellahi, R.; Riaz, A.; Nadeem, S.; Ali, M. Peristaltic flow of Carreau fluid in a rectangular duct through a porous medium. Math. Probl. Eng. 2012, 2012. [CrossRef]

35. Machireddy, G.R.; Polarapu, P.; Bandari, S. Effects of magnetic field and Ohmic heating on viscous flow of a nanofluid towards a nonlinear permeable stretching sheet. J. Nanofluids 2016, 5, 459-470. [CrossRef]

36. E, J.; Jin, Y.; Deng, Y.; Zuo, W.; Zhao, X.; Han, D.; Peng, Q.; Zhang, Z. Wetting models and working mechanisms of typical surfaces existing in nature and their application on superhydrophobic surfaces: A review. Adv. Mater. Interfaces 2018, 5, 1701052. [CrossRef]

37. Krisna, P.M.; Sandeep, N.; Sugunamma, V. Effects of radiation and chemical reaction on MHD convective flow over a permeable stretching surface with suction and heat generation. Walailak J. Sci. Technol (WJST) 2015, 12, 831-847. [CrossRef] 
38. Sandeep, N.; Sulochana, C.; Sugunamma, V. Radiation and magnetic field effects on unsteady mixed convection flow over a vertical stretching/shrinking surface with suction/injection. Ind. Eng. Lett. 2015, 5, 127-136.

39. Jonnadula, M.; Polarapu, P.; Reddy, G.; Venakateswarlu, M. Influence of thermal radiation and chemical reaction on MHD flow, heat and mass transfer over a stretching surface. Procedia Eng. 2015, 127, 1315-1322. [CrossRef]

40. Datta, N.; Jana, R.N. Oscillatory magnetohydrodynamic flow past a flat plate with Hall effects. J. Phys. Soc. Jpn. 1976, 40, 1469-1474. [CrossRef]

41. Aboeldahab, E.M.; Elbarbary, E.M. Hall current effect on magnetohydrodynamic free-convection flow past a semi-infinite vertical plate with mass transfer. Int. J. Eng. Sci. 2001, 39, 1641-1652. [CrossRef]

42. Biswal, S.; Sahoo, P. Hall effect on oscillatory hydromagnetic free convective flow of a visco-elastic fluid past an infinite vertical porous flat plate with mass transfer. In Proceedings-National Academy of Sciences India Section A; Springer Nature: Basel, Switzerland, 1999; pp. 45-58.

43. Changal, R.M.; Ananda, R.N.; Vijaya, K.V.S. Hall-current effects on unsteady MHD flow between stretching sheet and an oscillating porous upper parallel plate with constant suction. Therm. Sci. 2011, 15, 527-536. [CrossRef]

44. Rajput, U.; Kanaujia, N. Chemical reaction in MHD flow past a vertical plate with mass diffusion and constant wall temperature with hall current. Int. J. Eng. Sci. Technol. 2016, 8, 28-38. [CrossRef]

45. Shah, Z.; Dawar, A.; Khan, I.; Islam, S.; Ching, D.L.C.; Khan, A.Z. Cattaneo-Christov model for electrical magnetite micropoler Casson ferrofluid over a stretching/shrinking sheet using effective thermal conductivity model. Case Stud. Therm. Eng. 2019, 13, 100352. [CrossRef]

46. Ullah, A.; Alzahrani, E.O.; Shah, Z.; Ayaz, M.; Islam, S. Nanofluids thin film flow of Reiner-Philippoff fluid over an unstable stretching surface with Brownian motion and thermophoresis effects. Coatings 2019, 9, 21. [CrossRef]

47. Alharbi, S.O.; Dawar, A.; Shah, Z.; Khan, W.; Idrees, M.; Islam, S.; Khan, I. Entropy generation in MHD eyring-powell fluid flow over an unsteady oscillatory porous stretching surface under the impact of thermal radiation and heat source/sink. Appl. Sci. 2018, 8, 2588. [CrossRef]

48. Hayat, T.; Ahmed, B.; Abbasi, F.; Alsaedi, A. Numerical investigation for peristaltic flow of Carreau-Yasuda magneto-nanofluid with modified Darcy and radiation. J. Therm. Anal. Calorim. 2019, 137, 1359-1367. [CrossRef]

49. Carreau, P.; Kee, D.D.; Daroux, M. An analysis of the viscous behaviour of polymeric solutions. Can. J. Chem. Eng. 1979, 57, 135-140. [CrossRef]

50. Reddy, P.S.; Chamkha, A.J. Soret and Dufour effects on MHD convective flow of $\mathrm{Al}_{2} \mathrm{O}_{3}-\mathrm{water}$ and $\mathrm{TiO}_{2}-\mathrm{water}^{-}$ nanofluids past a stretching sheet in porous media with heat generation/absorption. Adv. Powder Technol. 2016, 27, 1207-1218. [CrossRef]

51. Ghadikolaei, S.; Hosseinzadeh, K.; Yassari, M.; Sadeghi, H.; Ganji, D. Analytical and numerical solution of non-Newtonian second-grade fluid flow on a stretching sheet. Therm. Sci. Eng. Progress 2018, 5, 309-316. [CrossRef]

52. Ghadikolaei, S.; Hosseinzadeh, K.; Ganji, D.; Hatami, M. $\mathrm{Fe}_{3} \mathrm{O}_{4}-\left(\mathrm{CH}_{2} \mathrm{OH}\right)_{2}$ nanofluid analysis in a porous medium under MHD radiative boundary layer and dusty fluid. J. Mol. Liq. 2018, 258, 172-185.

53. Hosseinzadeh, K.; Alizadeh, M.; Ganji, D. Hydrothermal analysis on MHD squeezing nanofluid flow in parallel plates by analytical method. Int. J. Mech. Mater. Eng. 2018, 13, 4. [CrossRef]

54. Sheikholeslami, M.; Shah, Z.; Shafee, A.; Khan, I.; Tlili, I. Uniform magnetic force impact on water based nanofluid thermal behavior in a porous enclosure with ellipse shaped obstacle. Sci. Rep. 2019, 9, 1196. [CrossRef] [PubMed]

55. Reddy, B.P. Hall effect on MHD transient flow past an impulsively atarted infinite horizontal porous plate in a rotating system. Int. J. Appl. Mech. Eng. 2018, 23, 471-483. [CrossRef]

56. Ahmad Farooq, A.; Shah, Z.; O Alzahrani, E. Heat transfer analysis of a magneto-bio-fluid transport with variable thermal viscosity through a vertical ciliated channel. Symmetry 2019, 11, 1240. [CrossRef]

57. Vo, D.D.; Shah, Z.; Sheikholeslami, M.; Shafee, A.; Nguyen, T.K. Numerical investigation of MHD nanomaterial convective migration and heat transfer within a sinusoidal porous cavity. Phys. Scr. 2019, 94, 115225. [CrossRef] 
58. Olajuwon, I.B. Convection heat and mass transfer in a hydromagnetic Carreau fluid past a vertical porous plate in presence of thermal radiation and thermal diffusion. Therm. Sci. 2011, 15, 241-252. [CrossRef]

59. Hassani, M.; Tabar, M.M.; Nemati, H.; Domairry, G.; Noori, F. An analytical solution for boundary layer flow of a nanofluid past a stretching sheet. Int. J. Therm. Sci. 2011, 50, 2256-2263. [CrossRef]

60. Sha, Z.; Dawar, A.; Alzahrani, E.O.; Kumam, P.; Khan, A.J.; Islam, S. Hall effect on couple stress 3D nanofluid flow over an exponentially stretched surface with cattaneo christov heat flux model. IEEE Access 2019, 7, 64844-64855. [CrossRef]

61. Liao, S.J. The Proposed Homotopy Analysis Technique for the Solution of Nonlinear Problems. Ph.D. Thesis, Shanghai Jiao Tong University, Shanghai, China, 1992.

62. Ellahi, R. The effects of MHD and temperature dependent viscosity on the flow of non-Newtonian nanofluid in a pipe: Analytical solutions. Appl. Math. Model. 2013, 37, 1451-1467. [CrossRef]

63. Gul, T.; Khan, M.A.; Khan, A.; Shuaib, M. Fractional-order three-dimensional thin-film nanofluid flow on an inclined rotating disk. Eur. Phys. J. Plus 2018, 133, 500. [CrossRef]

(C) 2020 by the authors. Licensee MDPI, Basel, Switzerland. This article is an open access article distributed under the terms and conditions of the Creative Commons Attribution (CC BY) license (http:/ / creativecommons.org/licenses/by/4.0/). 